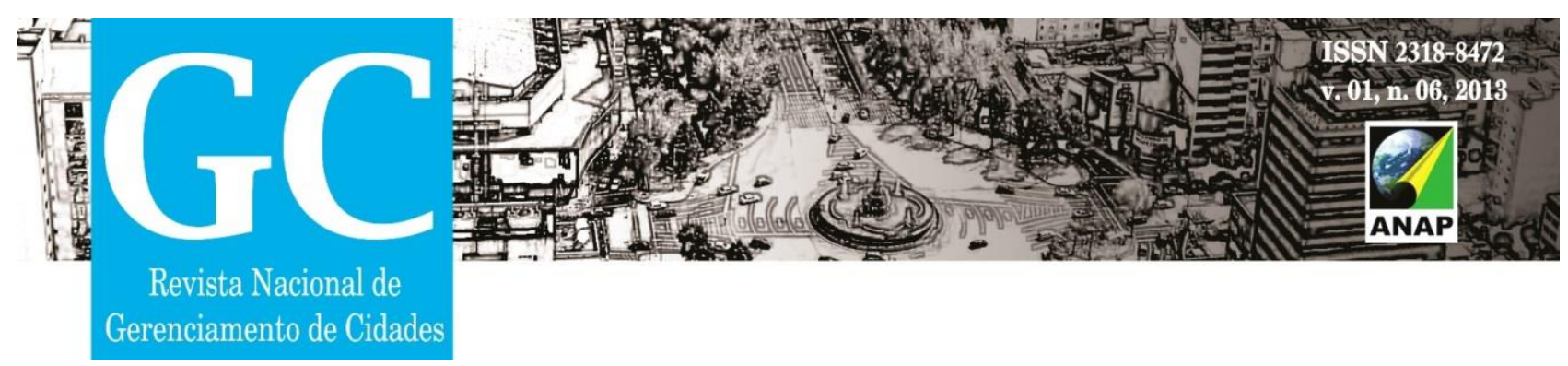

\title{
GESTÃO DA CONTRUÇÃO CIVIL NO AMBIENTE URBANO: CONSIDERAÇÕES SOBRE CONSEQÜÊNCIAS E DESDOBRAMENTOS
}

Lucas Devides Moreno ${ }^{1}$

Bruno Borges Mamede ${ }^{2}$

Resumo: Este artigo visa responder ao questionamento acerca dos efeitos da má gestão de obras em Construção Civil, tanto para a cidade como para a sociedade, indicando alguns problemas e soluções percebidos na realização de obras. A partir da análise das diversas etapas de projeto e a observação do conceito de sustentabilidade pretende-se demonstrar como o gerenciamento pode ser utilizado como ferramenta de eficiência e controle para melhores práticas neste setor.

Palavras-Chave: Engenharia Urbana. Engenharia Civil. Sustentabilidade. Gestão de Obras e Construções.

\section{1- INTRODUÇÃO}

É muito comum e freqüente, falhas na construção civil, geralmente ocasionada devido à má gestão das etapas construtivas como, falhas nos projetos, falhas na execução, materiais inadequados, manutenção e conservação do serviço já executado. Quando se pensa em uma dinâmica urbana a falha neste gerenciamento de projetos pode

\footnotetext{
${ }^{1}$ PEU/POLI/UFRJ / lucas.moreno@poli.ufr..br

2 PEU/POLI/UFRJ / lucas.moreno@poli.ufrj.br
} 


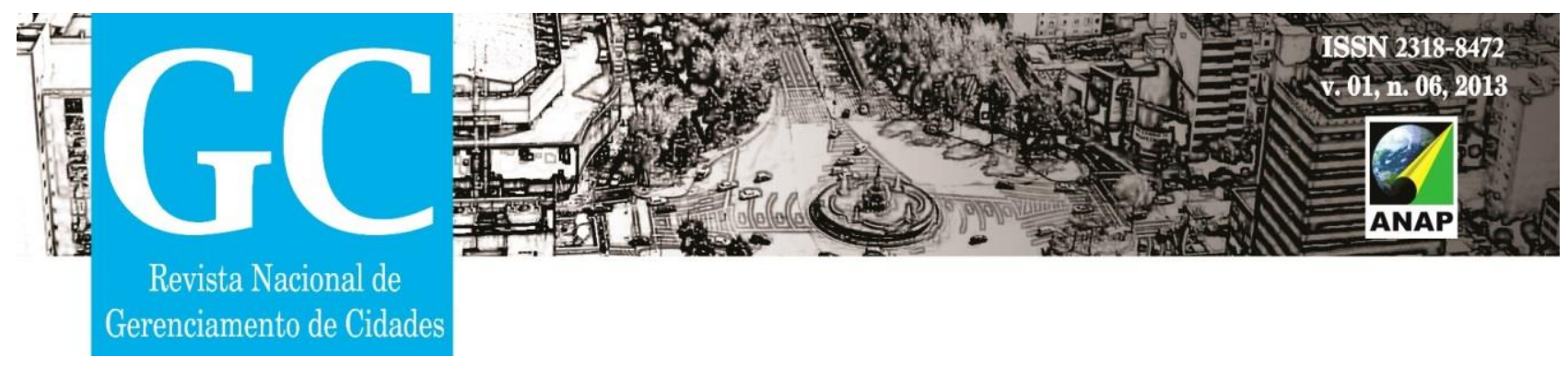

acarretar atrasos em obras onde a mesma, poderia beneficiar a população da cidade, colocar em risco a segurança de pessoas em seu entorno, prejuízos financeiros, devidos a retrabalho, prejuízos ambientais, onde o freqüente desperdício de matérias utilizado na construção civil tem como origem fonte natural não renovável, a falta de manutenção e conservação das obras já existentes, entre outras.

O ambiente construído hoje é muito dependente da construção civil, pois são frutos dele que proporciona às habitações, os espaços de lazer, a infraestrutura de transporte, saneamento básico, etc. A construção Civil no Brasil é parte importante no desenvolvimento econômico e social do país. Por outro lado, é um setor produtivo que gera grandes impactos ambientais, quer seja pelo consumo de recursos naturais, geração de resíduos ou alteração na paisagem física da cidade.

Segundo Souza e Deana (2007), a indústria da construção civil consome de 100 a 200 vezes mais material que a indústria automobilística. A cadeia produtiva da construção é responsável pelo consumo de $14 \%$ a $50 \%$ dos recursos naturais extraídos no planeta. No Japão responde por $50 \%$ dos materiais circulantes na economia e, nos Estados Unidos, relaciona-se a $75 \%$ dos materiais. Onde este dado, de certa forma, vem como um alerta que o Brasil, pelo seu forte crescimento tende a aumentar ainda mais este consumo de recursos naturais.

Ainda Segundo Souza e Deana (2007), os recursos financeiros aplicados apenas em materiais representam metade do custo de uma obra. No entanto, além dos recursos financeiros, a construção de habitações no Brasil envolve o consumo de grandes quantidades destes recursos do nosso planeta, haja em vista que um metro quadrado de construção utiliza, grosseiramente, uma tonelada de materiais.

Devido a um grande número de materiais envolvidos na construção civil, às vezes o setor da construção é usado de maneira inadequada, pelas nossas políticas econômicas. $\mathrm{O}$ fato da construção civil gerar muitos empregos, abranger diversas áreas da economia, algumas políticas habitacionais como o programa minha casa e minha vida como é chamado hoje, tem como maior objetivo uma política econômica e não uma política social. A população muitas vezes compra a idéia, sem olhar o ônus que terá mais 


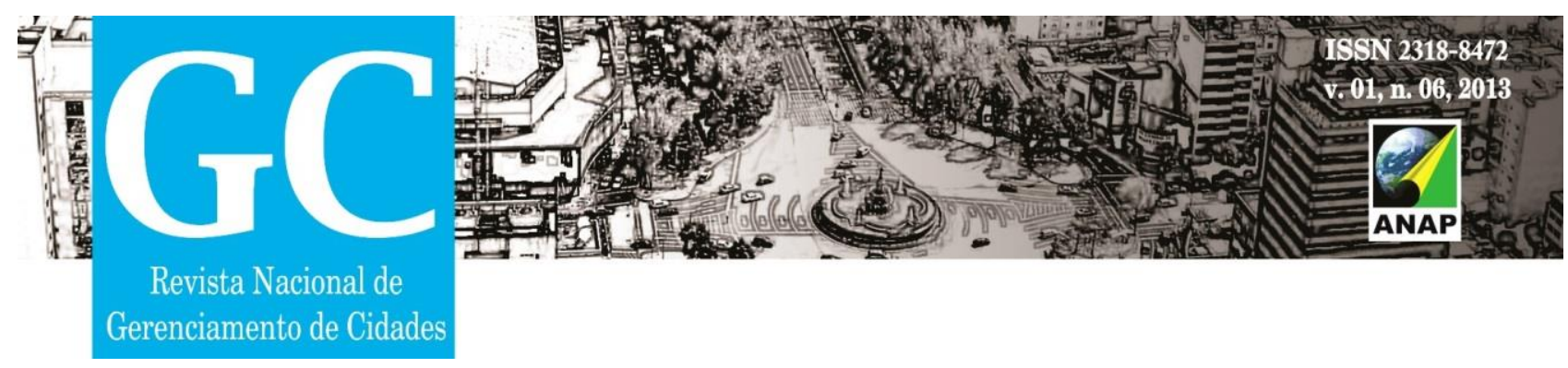

a frente, onde o fato de uma cidade estar crescendo é completamente diferente de ela estar se desenvolvendo. Onde planejar o desenvolvimento de uma cidade é umas das tarefas mais difíceis do poder publico.

Com este boom da construção civil, e a necessidade de manutenção econômica, faz-se necessário criar projetos e obras novas, sem mesmo que elas sejam bem estudas, pois a real intenção dos governantes é justamente a manutenção econômica, deixando de lado políticas de redução de consumo de materiais, projetos mais bem elaboradas, obras melhores gerenciadas e mais bem planejadas.

Segundo Moisés (1999), a idéia de crescimento - que sugere principalmente aumento em quantidade - a de desenvolvimento implica a mudança de qualidade e, também, aumento dos graus de complexidade, integração e coordenação de um sistema. Crescimento exige material e energia. Desenvolvimento produz e se alimenta de interações, informações e principalmente planejamento e gestão.

Quando se entende o conceito de sustentabilidade, onde o mesmo atinge três esferas importantíssimas como, social, financeira e respeito ao meio ambiente, deixa confortável a diferenciação de quando uma cidade cresce ou se desenvolve sustentavelmente.

Segundo Corrêa (2009), o tema referente à sustentabilidade foi abordado inicialmente na década de 80 com o relatório de Brundtland (1987) e era, enquanto definição geral: "suprir as necessidades da geração presente sem afetar a habilidade das gerações futuras de suprir as suas". Desde então, pesquisas e estudos em todo mundo levariam a tópicos relevantes para que se tenha uma construção sustentável nos parâmetros vigentes quanto às questões ambientais.

A metodologia utilizada neste texto consta em uma revisão bibliográfica a fim de mostrar os efeitos causados devido a uma má gestão na construção civil, não só para cidade como para população como um todo. Onde no desenvolvimento do texto será discutido como uma cidade se desenvolva sustentavelmente, serão abordados as três etapas de constituintes na construção de um empreendimento;

- Concepção; 


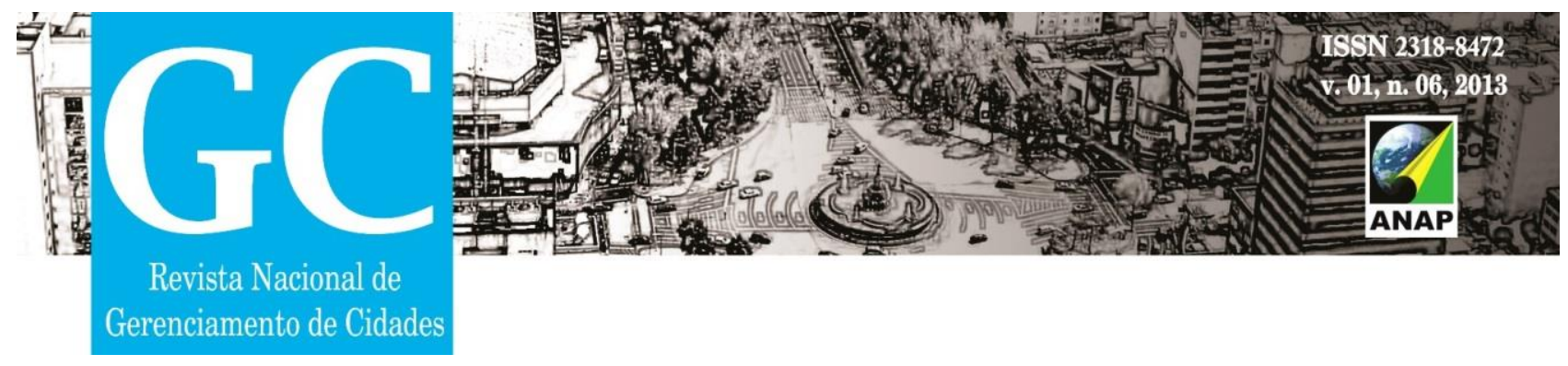

- Produção;

- Uso e Manutenção.

\section{2- JUSTIFICATIVA}

Nas obras de construção civil hoje no Brasil, apresentam sempre falhas características em seu projeto, devido às falhas desde a concepção do projeto, produção e uso/manutenção das obras. Pode-se dizer que estas falhas alem de trazerem grandes prejuízos financeiros, como social e danos irreparáveis ao meio ambiente.

Segundo Araújo (2013), o nosso ambiente construído é responsável por $75 \%$ no consumo de materiais, onde $90 \%$ destes materiais são matérias não renováveis, se este consumo continuar de maneira desordenada, logo se extinguirá trazendo problemas para geração futura.

Como o sistema construtivo em obras civis no Brasil, ainda é feito de maneira precário, são comuns atrasos em obras, desperdício de materiais por falha no planejamento, condições sub-humanas de trabalho dentro dos canteiros de obra, muitas vezes expondo a integridade física e social dos seus trabalhadores, onde esta relação esta totalmente relacionada com o desempenho final da obra.

\section{3- OBJETIVO}

Todo histórico que tem, relacionado à construção civil hoje, aponta que a mesma sempre existiu para atender as necessidades básicas e imediatas do homem sem a preocupação com a técnica aprimorada em um primeiro momento. Onde as concepções e execução de projetos relacionados à construção, nunca deram a importância devido ao consumo de materiais. Após anos e anos de construção no mundo, constatou-se que o setor da construção civil é muito dependente a recursos naturais não renováveis, onde se ele continuar de maneira desordenada extinguiria a raça uma, pois é impossível manter uma sobrevivência na terra sem tais recursos naturais. 


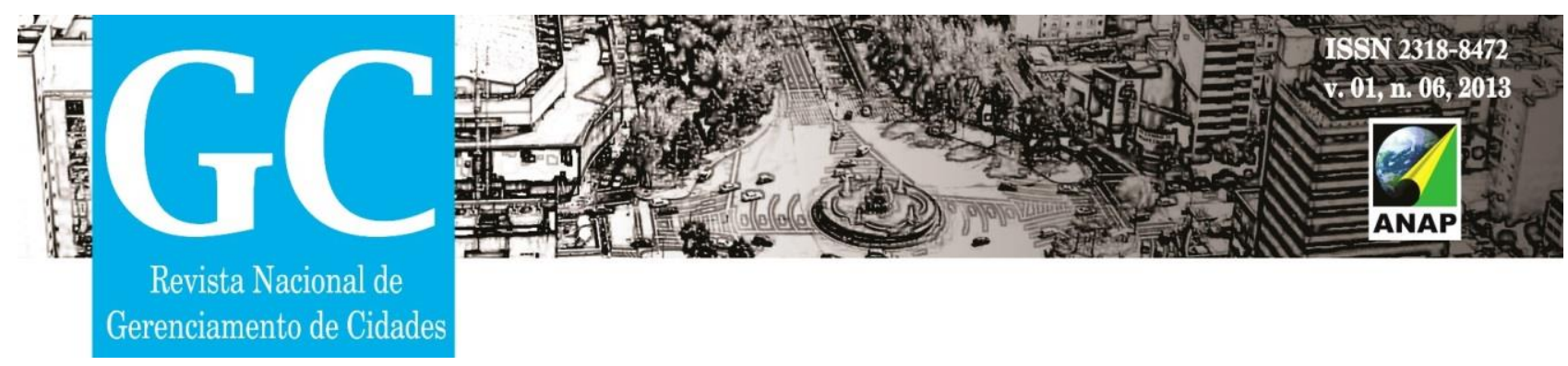

Com todo cultura de destruição que tem-se hoje, ainda persevera uma lado positivo da população de não se auto-destruir, dado este fato nasce então um dos assuntos mais discutidos hoje que é a sustentabilidade na construção civil. A fim de minimizar esse consumo desordenado de fontes naturais não renováveis o principal objetivo deste texto é entender o processo evolutivo das etapas de construção de um projeto, indo da sua concepção, seguindo até sua parte de produção, chegando por fim no seu uso/manutenção.

\section{4- DESENVOLVIMENTO}

Para que um projeto de construção civil seja taxado com sucesso, o mesmo tem como obrigação atender três requisitos básicos:

- Deve ser financeiramente satisfatório;

- Deve atender as necessidades sociais da cidade;

- Deve estar em harmonia com a dinâmica da cidade e respeitando o meio ambiente.

Para que isto seja possível primeiramente faz se necessário compreender quais as etapas de um empreendimento.

Segundo Souza e Deana (2007), simplificadamente, um empreendimento pode ser considerado como contemplando três grandes etapas, como mostra na Figura 1 abaixo: a da Concepção, onde além de uma série de outras decisões, definem-se: o produto que será executado; a da produção, onde tal produto é construído; e a da utilização, onde o produto é usado e mantido/reparado até o final da sua vida útil.

Figura 1 - Etapas do Empreendimento 

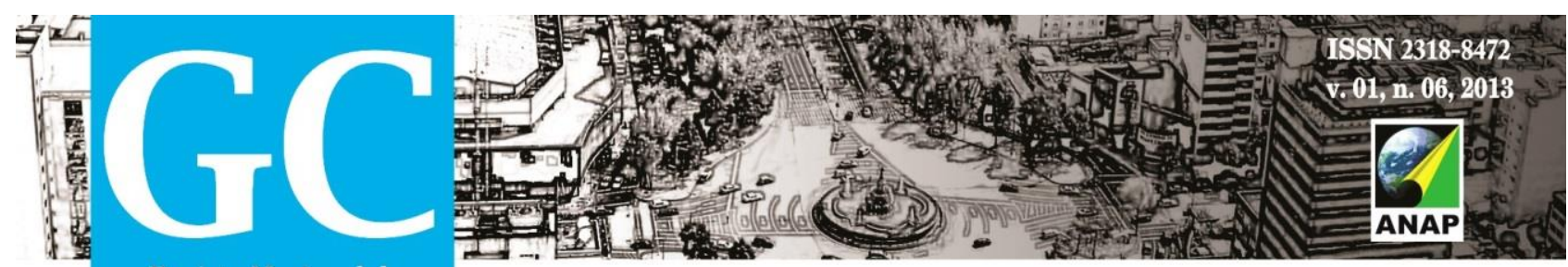

Revista Nacional de

Gerenciamento de Cidades

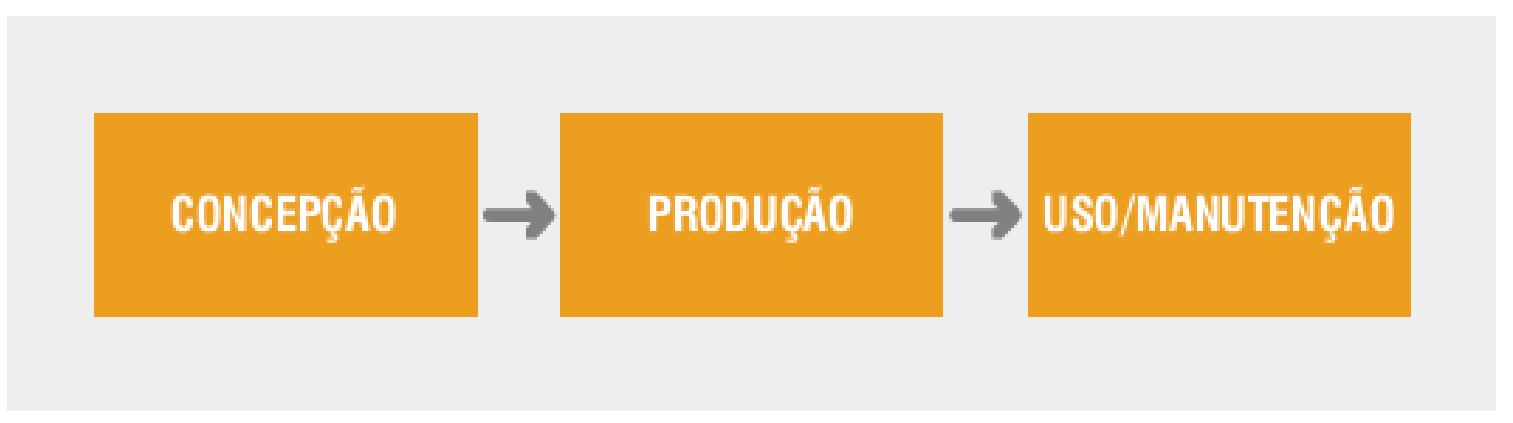

Fonte: Souza e Deana (2007)

\section{1 - CONCEPÇÃO DE UM PROJETO DE CONSTRUÇÃO CIVIL}

Muito mais do que a execução da obra, construir um empreendimento é uma missão extremamente elaborada, onde requer uma análise criteriosa, para que não tenha um desperdício de material excessivo, pois o mesmo é diretamente proporcional no produto final da obra. Com isso, hoje um projeto de construção é indispensável atualmente, quanto a custo, tempo e como já dito exploração de recursos, são itens fundamentais ao construtor.

O Centro de Tecnologia de Edificações (CTE) define que um projeto de engenharia é o guia de execução de uma obra. São importantes pares as necessidades do usuário sejam entendidas e transformadas nas melhores soluções arquitetônica, o que inclui não só a estética como as condições de habitação, acesso e conforto. Na fase de projeto, ainda pode-se ser estudada soluções para uma melhor eficiência das edificações, como por exemplo, economia de energia e reuso de água, gerando uma economia no custo da operação após a entrega.

Para exemplificar a importância de uma boa concepção de projeto, Souza e Deana (2007), afirmam que ao que refere à etapa de concepção, embora não haja consumo de materiais propriamente dito, pois esta etapa consiste apenas no nível de idéias, é uma etapa de suma importância, pois a mesma tem uma grande influencia quanto à definição do futuro consumo de materiais por metro quadrado de obra a ser produzido.

Abaixo terá dois exemplos retirados do documento elaborado pelo Souza e Deana (2007), o primeiro (Figura 2), mostrado que a projeção de um prédio com a mesma área 

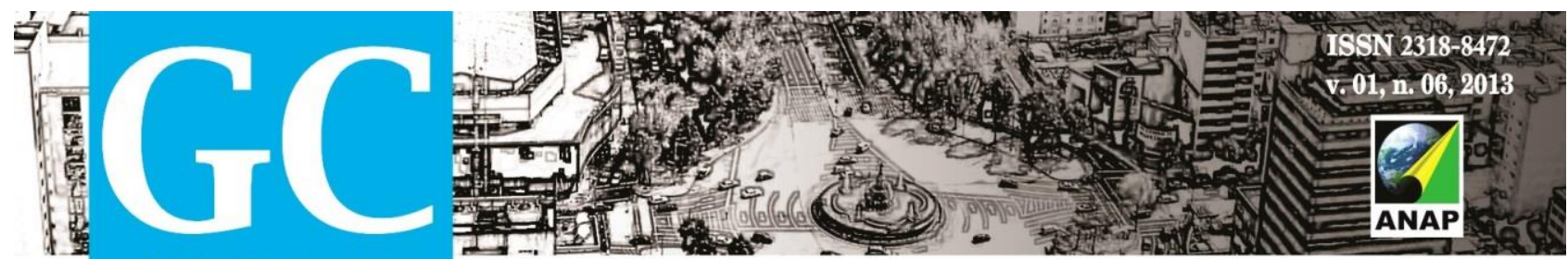

Revista Nacional de

Gerenciamento de Cidades

tem perímetros diferentes, acarretando assim um maior consumo de revestimento da fachada. Já o segundo (Figura 3), mostra um gasto excessivo de concreto na varando, pelo fato do projeto da varanda (caso A), não considerar um rebaixo na laje da varanda, tendo que crescer a espessura do contra piso de dentro do apartamento, a fim de manter o rebaixo convencional necessário entre a varanda $\mathrm{x}$ apartamento.

Figura 2 - Área de projeção da planta de dois empreendimentos

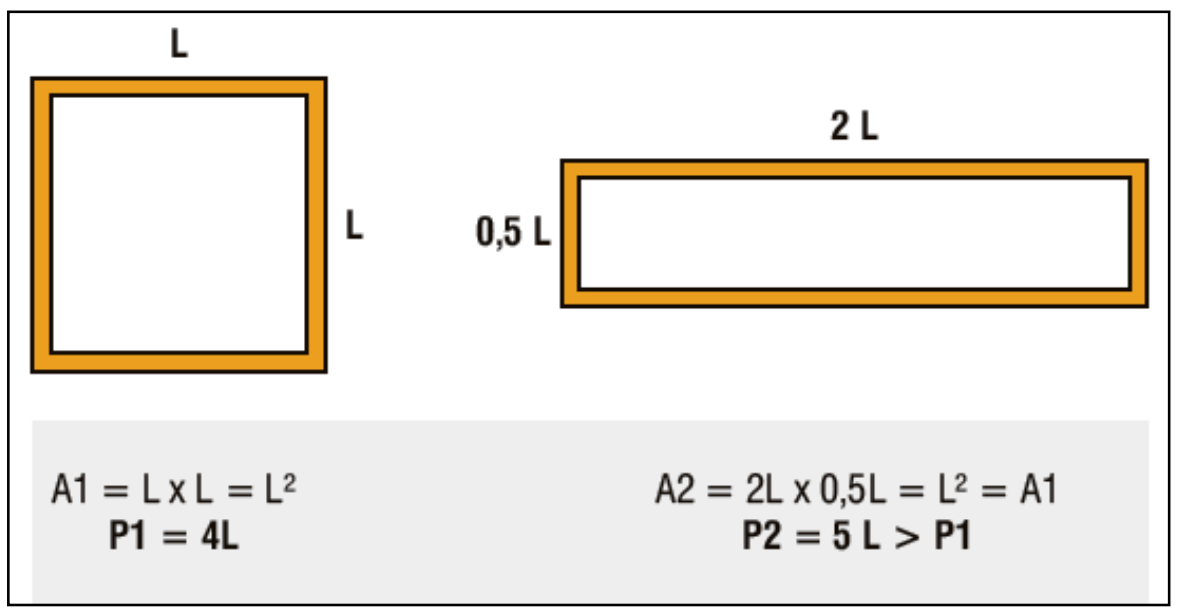

Fonte: Souza e Deana (2007)

Figura 3 - Corte transversal detalhando as espessuras mínimas de ontra piso

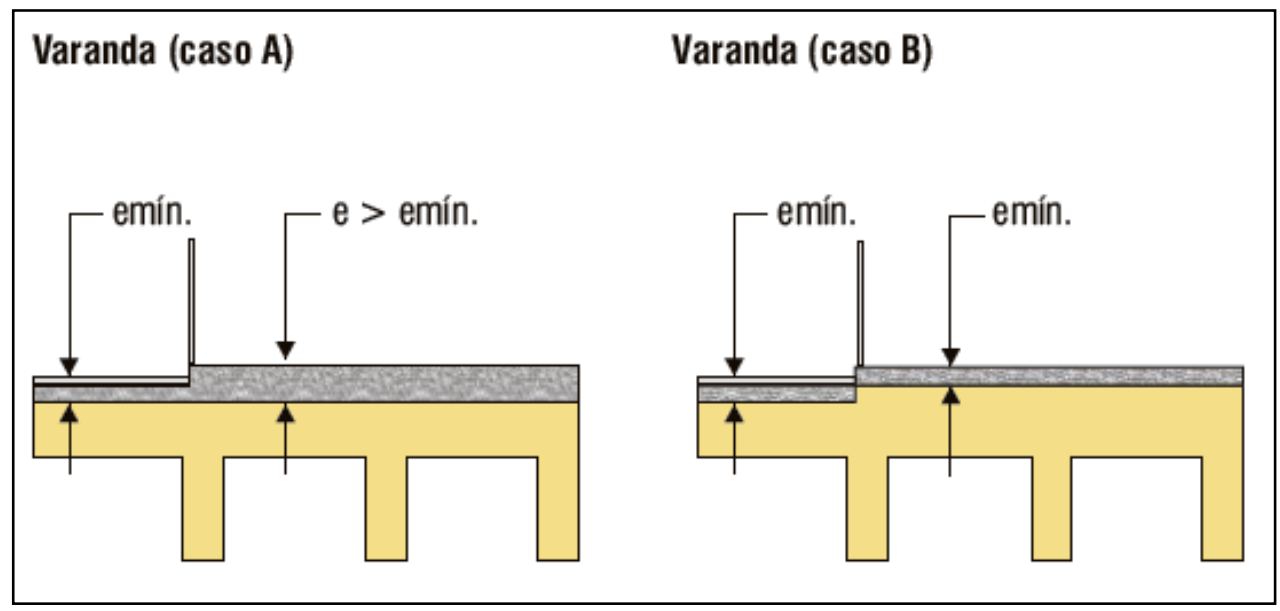

Fonte: Souza e Deana (2007) 


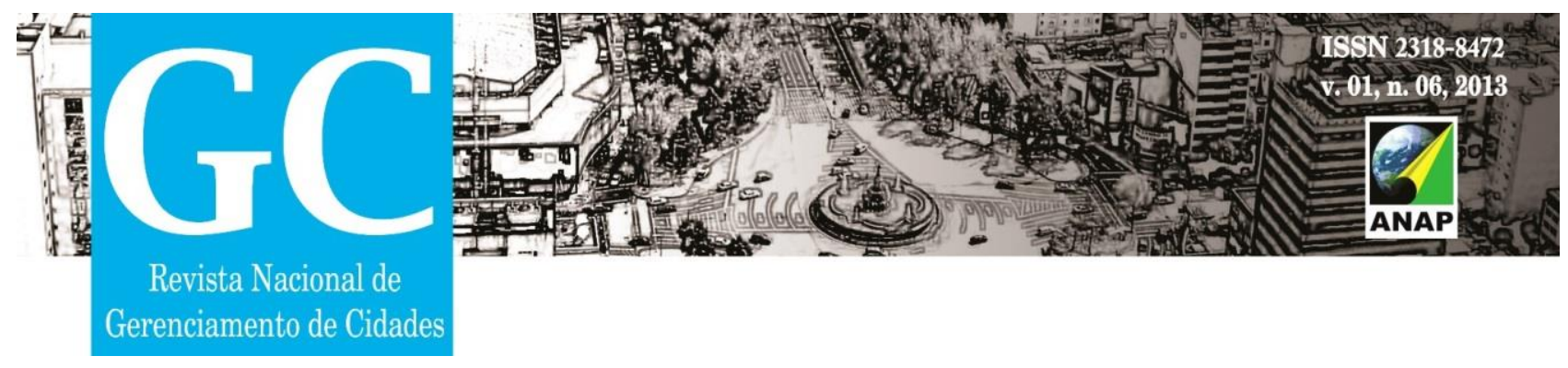

Percebe-se, que a fase de concepção de projeto, já há uma preocupação com a racionalização de materiais provenientes a recursos naturais não renováveis. Entende-se que nesta etapa o problema é meramente técnico, onde certamente cada dia que passa os projetos vem sendo melhores confeccionados. Para uma boa concepção de projetos executivos, como já dito o lado técnico prevalece, cabendo único e exclusivamente a um arquiteto ou engenheiro resolve-lo, sendo que no futuro se estes profissionais não atender os pré-requisitos de um projeto sustentável, os mesmos serão eliminados do mercado, funcionando como uma espécie de seleção natural, extinguindo os projetos não sustentáveis.

\section{2 - PRODUÇÃO DE UM PROJETO DE CONSTRUÇÃO CIVIL}

Já na etapa de produção do projeto, não pode ser tratada exclusivamente como uma solução técnica de engenharia, pois a mesma abrange outras esferas, pelo fato de ter mais gente envolvida. Sabe-se que não se faz uma obra sozinho, dependendo do porte de um empreendimento residencial de prédios, por exemplo, pode chegar a mais de 1.000 trabalhadores, para um único objetivo.

Segunda Souza (2001), a mão-de-obra no caso é o recurso mais precioso participante da execução de obras de construção civil, não somente porque representa a alta porcentagem do custo total, mas, principalmente, em função de estar lidando com seres humanos, que têm uma série de necessidades que devem ser supridas. Onde a medição desta produtividade passa a ser uma ferramenta muito importante para a gestão de mão-de-obra, podendo substituir políticas para redução de custos e aumento na motivação no trabalho.

Ainda segundo Souza (2001), considera-se que a produtividade seja a eficiência em se transformar entradas e saídas num processo produtivo. Dentro desta definição, a Figura 4 abaixo mostra as diferentes abrangências do estudo da produtividade, no processo de produção de obras de construção civil. 


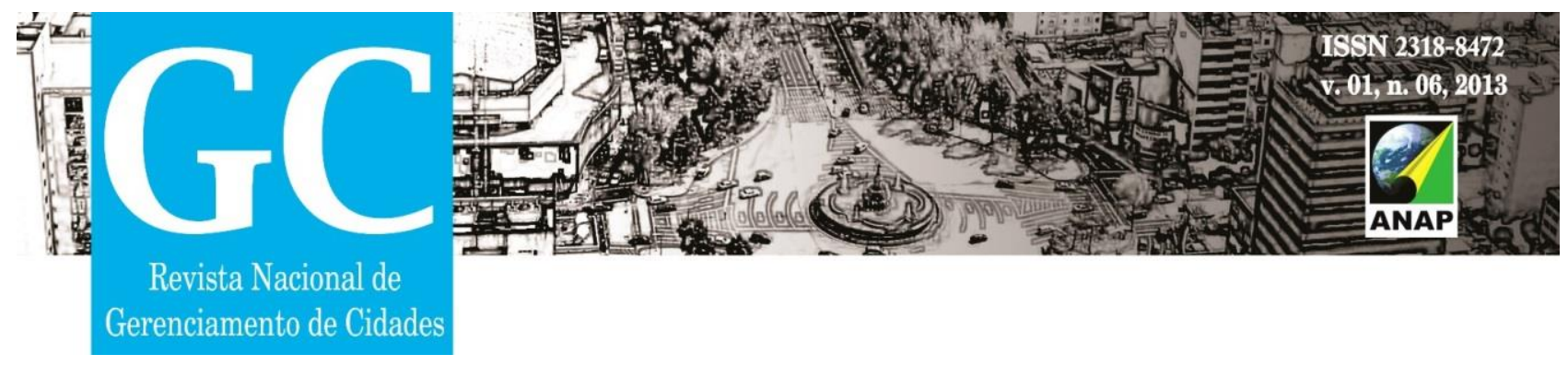

Figura 4 - Diferentes abrangências do estudo da produtividade

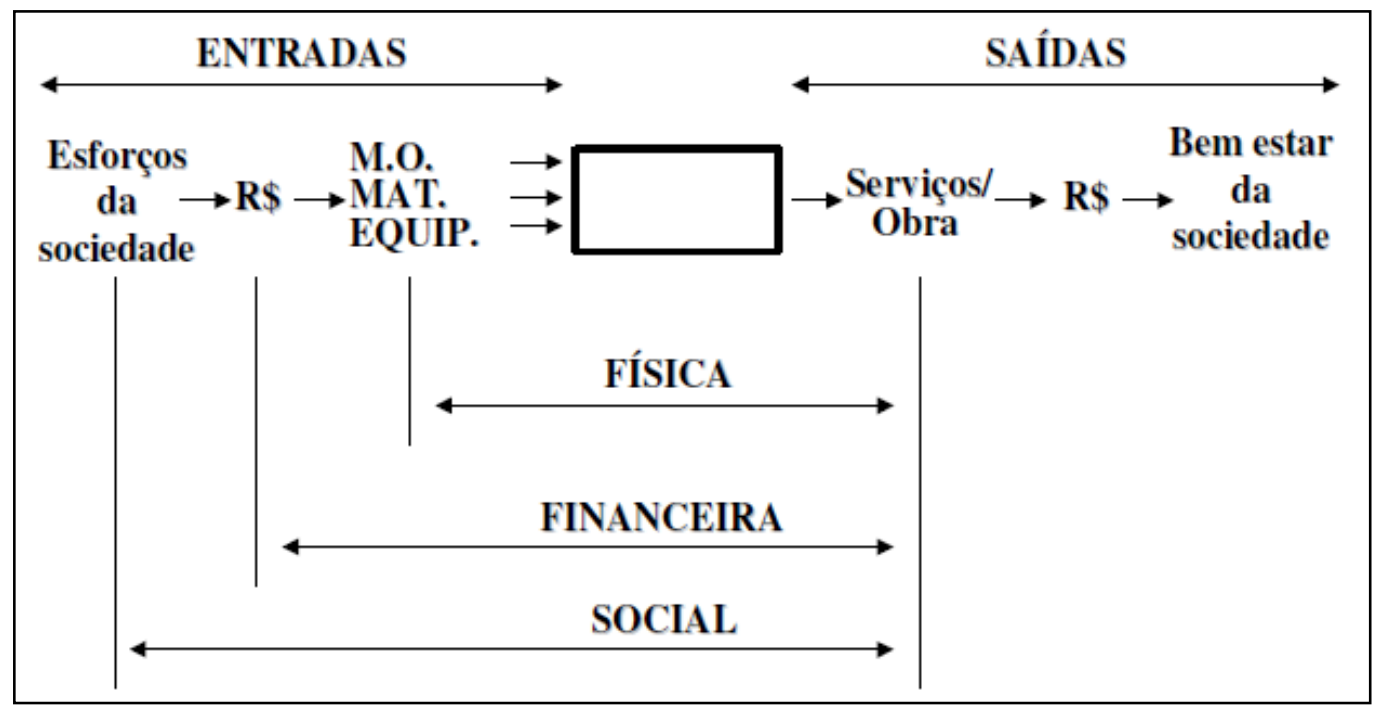

Fonte: Souza (2001)

A figura acima mostra claramente os três fatores, relacionados a produção de um projeto de construção civil, abaixo segue a definição dada pelo Souza (2001);

- Físico; no caso de se estar estudando a produtividade no uso dos materiais, equipamentos e mão-de-obra;

- Financeiro; quando a análise recai sobre a quantidade de dinheiro demandado;

- Social; quando o esforço da sociedade como um todo é encarado como recurso inicial do processo.

Nesta etapa de produção é onde todo material da construção é demandado. Segundo Souza e Deana (2007), é nesta fase que se associam as reclamações quanto a se ter gasto mais material que o esperado e onde surgem problemas com resíduos gerados. Onde erros, no ato da produção, devido a obra desorganizada, retrabalho, são responsáveis por aumentar o consumo de materiais nos canteiros. Percebe-se que fatos 


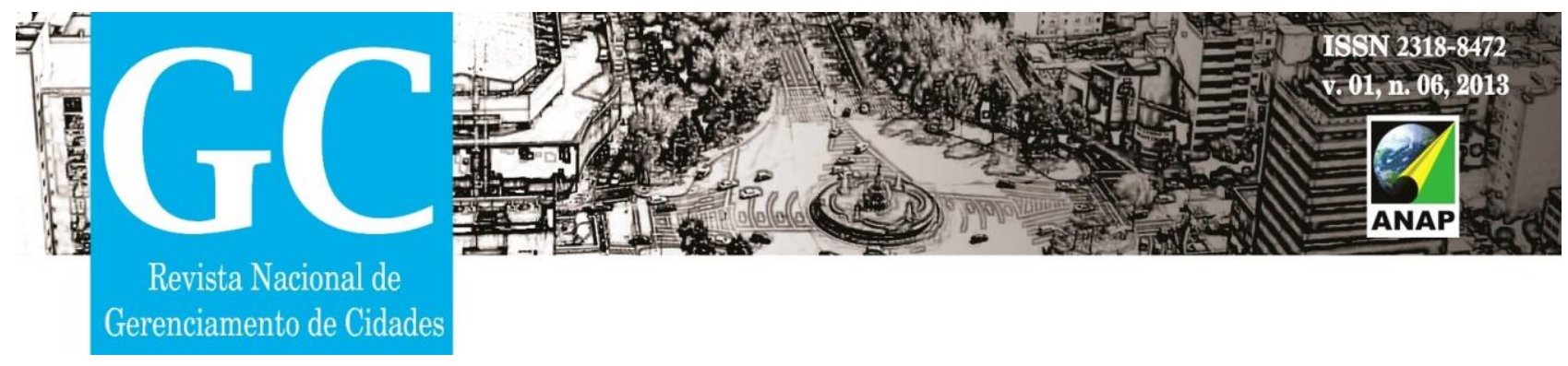

como estes nas obras abrangem o três fatores descritos acima. Na parte física, devido aos retrabalhos, há uma perda na produtividade, no quesito financeiro, este consumo excessivo de material encarece a obra, diminuindo a margem de lucro dos empreendedores, já o quesito social, não é tão fácil assim relacionar estes empecilhos, uma vez que a baixa produtividade de uma obra pode esta diretamente relacionada, com as condições dos trabalhadores fora e dentro dos canteiros. Por exemplo, a condição precária do transporte publica do funcionário até a obra, moradia com baixas condições de habitabilidade, a cidade não proporcionar espaços de lazer para a população, são fatores que afetam o desempenho de uma obra. Com isso, faz-se necessário, mitigar seu problema em sua origem. O primeiro passo é entender melhor os problemas de uma obra através de uma visão sistêmica do que esta influenciando os atrasos de obras, onde geram custos excessivos, consumo de materiais excessivos. Para isso deve-se romper com o paradigma da visão mecanicista que prevalece hoje em dia, tratando os problemas sempre através de técnicas.

\section{2 - USO E MANUTENÇÃO DE UM PROJETO DE CONSTRUÇÃO CIVIL}

Na etapa referente ao uso e manutenção de um projeto de construção. É de suma importância, para que o mesmo continue sendo taxado como um projeto sustentável.

No ato da concepção do projeto, os responsáveis técnicos devem, propor usar matérias de fácil conservação, onde com apenas um pintura anti corrosiva, pode melhorar muito a vida útil de uma estrutura metálica, uma pingadeira, ruffos, calhas, instalados sobre a platibanda e muros de prédios, podem ajudar a escorrer as águas provenientes das chuvas, diminuindo a necessidade de conservação das fachadas.

Segundo Corrêa (2009), a necessidade de demolição de edifícios existentes devido ao comprometimento de sua segurança estrutural ou obsolescência funcional pode ser evitada caso seja possível dar continuidade à ocupação da edificação. A melhor maneira de reduzir desperdícios advindos de uma demolição é exatamente evitar que ela ocorra, 


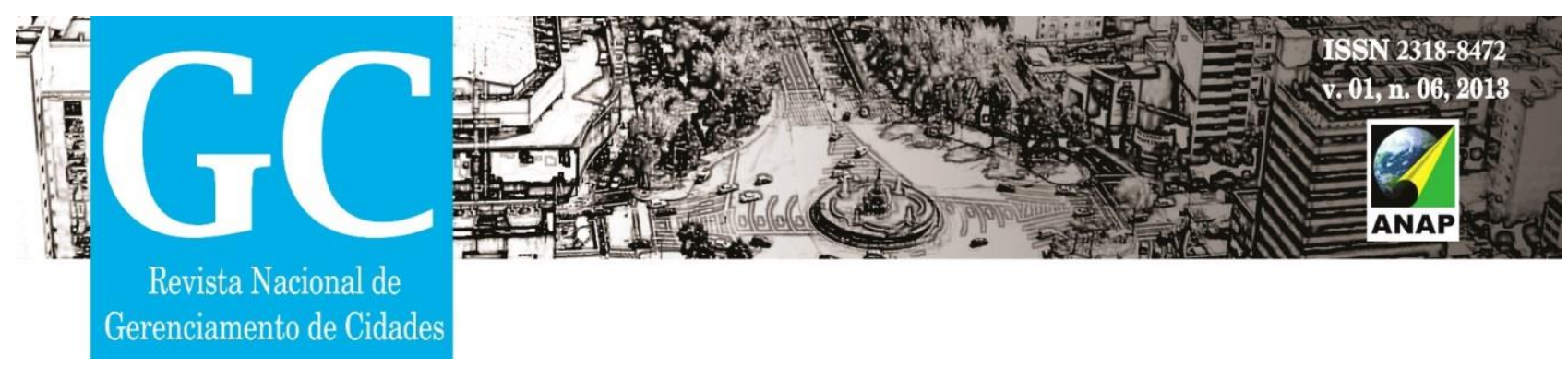

ao perpetuar o uso do edifício. A manutenção predial prolonga sua vida útil, proporciona a conservação e boa aparência da construção, mantém as condições de segurança estrutural e da construção como um todo.

Um imóvel que se encontra vazio ou abandonado devido a sua não adequação espacial ao uso anterior pode ser recuperado, recebendo uma nova destinação funcional. Ainda que sejam necessárias alterações no desenho interno ou pequenas reformas, seus custos serão sempre menores que sua derrubada para construção de um edifício novo.

Apenas exemplificando, o fato comentado acima, porém agora com um caso de infraestrutura urbana, segundo Mamede, Moreno e Júnior (2013), propôs a não demolição da avenida perimetral no Rio de janeiro, uma vez que devido ao crescimento urbano a mesma encontra-se saturada e não vem cumprido muito bem seu papel na circulação urbana. Porém a proposta consiste em não demolir a estrutura existente, onde o estudo apresenta a possibilidade de conversão em via ferroviária, completamente integrada aos principais eixos modais da cidade do Rio de Janeiro, em paralela a criação de novos terminais e corredores de circulação para o transporte público, além da requalificação de toda a área de entorno do projeto.

Esta etapa ainda contesta, onde algumas vezes o produto, segue cumprindo com seus requisitos básicos de utilização, porem por alguma razão seja ela por qual motivo, tendem a eliminá-lo, ou substituí-lo ou adicionar um novo elemento, implicando em consumo adicional de materiais, segundo Souza e Deana (2007), conhecido como "obsolescência funcional". Exemplo disso é a decisão pela repintura de um ambiente tendo como objetivo apenas a mudança de cor, ou a troca de um revestimento cerâmico em bom estado com o intuito de atender um novo padrão estético valorizado pelos usuários.

\section{5- CONSIDERAÇÕES FINAIS}

Após de um breve entendimento das etapas envolvidas em um processo de construção civil, o foco principal deste texto é concluir que para se ter um 


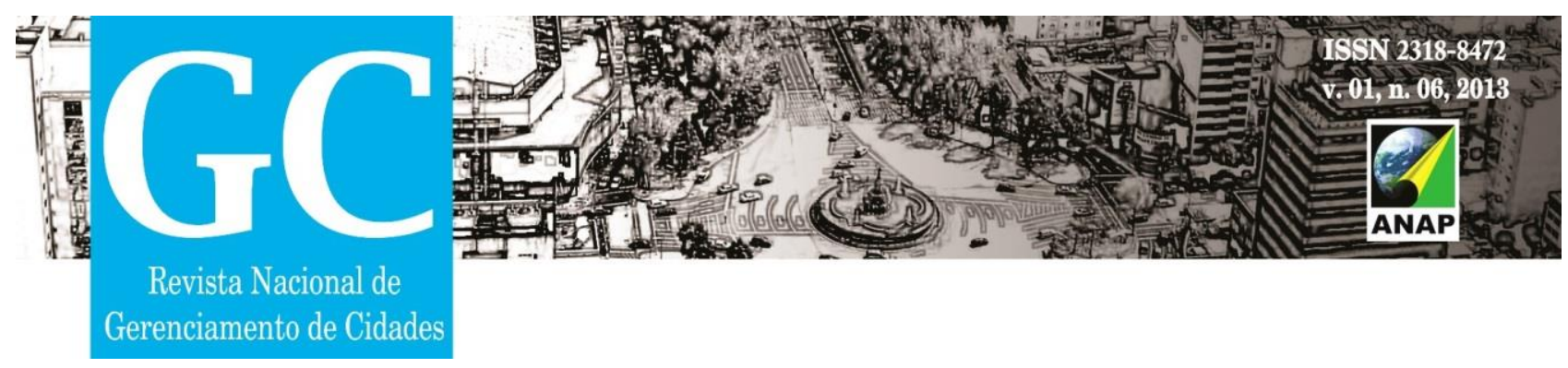

desenvolvimento sustentável nas cidades, a gestão da construção civil não deve se munir apenas de tratativas técnicas dadas por engenheiro, arquitetos.

A discussão sobre sustentabilidade avança e envolvem cada vez mais, profissionais de diversas áreas; e estes, em certos momentos se reúnem para trabalhar em conjunto na busca de soluções para este desafio proposto. Dado este fato, percebe-se já a implantação de um novo paradigma, onde o mesmo tem como prerrogativa uma visão integrada do problema. Segundo Corrêa (2009), o conceito de desenvolvimento sustentável é apresentado pela primeira vez na década de 80 pelo relatório Brundtland, aos temas relacionados aos sistemas que envolvem a Construção Civil. É feita uma reflexão sobre a real abrangência e o alcance destes conceitos de sustentabilidade ao tema principal da pesquisa, que é a sustentabilidade na construção civil.

Segunda a declaração de política de 2002 da Cúpula Mundial sobre desenvolvimento sustentável, realizada em Johannesburg, afirma que o Desenvolvimento Sustentável é construído sobre três pilares interdependentes e mutuamente sustentadores: desenvolvimento econômico, desenvolvimento social e proteção ambiental.

Então para que consiga projetos sustentáveis na construção civil, conclui-se que não basta soluções técnicas, precisa entender melhor e explorar o problema em sua raiz. Com isso, há uma preocupação maior no ato da produção de um empreendimento da construção civil, pois hoje mesmo com todas essas discussões de sustentabilidade presente, é comum encontrar;

- Condições desumanas para funcionários em obras de construção civil;

- Falta de uma política habitacional, para que os trabalhadores tenham direito a condições mínimas de moradia;

- Falta de uma política de transporte publico, para que os trabalhadores cheguem à obra de maneira tranqüila e justa;

- Funcionários da construção civil não se identificam mais com sua profissão, causando um falta de mão-de-obra especializada. 


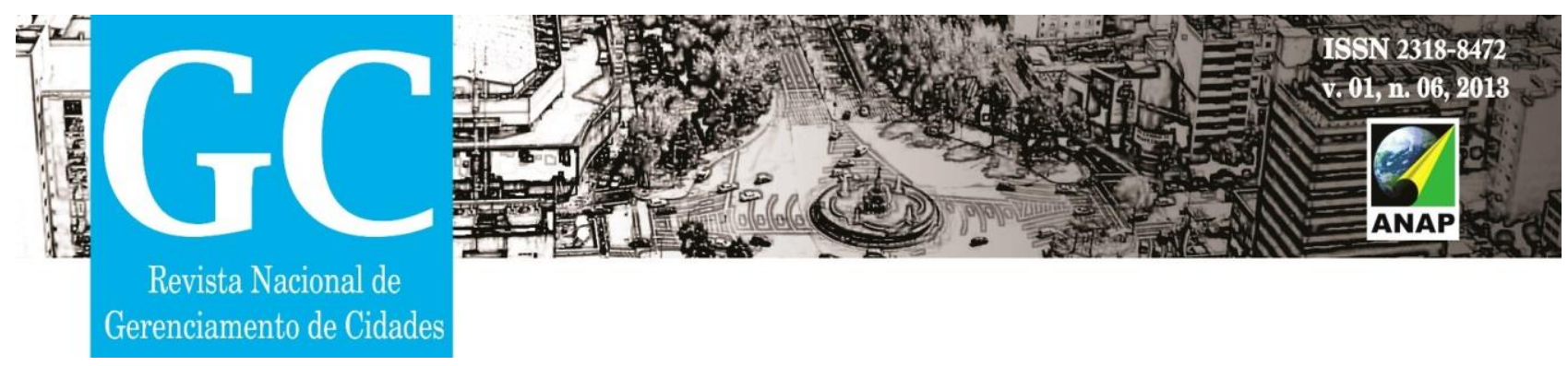

Os itens acima deixam claro que para buscar melhores desempenhos de produtividade que é totalmente proporcional a sustentabilidade, exclusivamante dentro dos canteiros de obra, e não olhar para o lado de fora a produtividade nas obras de construção civil continuara, não cumprindo os prazos acordados inicialmente, consumos excessivos de materiais, custos acima do previsto, causando danos irreparáveis na produção das cidades.

\section{REFERÊNCIAS}

ARAÚJO, L. O. C., Slides apresentados em aula de Gestão da Construção Civil. Mestrado Profissional em Engenharia Urbana - UFRJ, Rio de Janeiro, 2013.

CORRÊA, L. R. Sustentabilidade na Construção Civil. Monografia apresentada ao Curso de Especialização em Construção Civil da Escola de Engenharia UFMG, Belo Horizonte, 2009.

Conselho Brasileiro de Construção sustentável: www.cbcs.org.br. Acesso em 07/08/2013.

Centro de Referência e Informação em Habitação: www.infohab.org.br. Acesso em 16/08/2013.

GUERRA, J. S. Gestão de Resíduos da Construção Civil em Obras de Edificações. Dissertação aprresentada ao Curso de Pós-Graduação em Engenharia Civil, Da Escola Politécnica de Pernambuco da Universidade de Pernambuco para obtenção do título de Mestre em Engenharia Civil, Recife, 2009.

MAMEDE, B., MORENO, L. e SOARES JÚNIOR, L. Requalificação Urbana: Proposta Para uma Nova Perimetral. Artigo IX Fórum Ambiental - Alta Paulista, Tupã, 2013.

MOISÉS, H. O Município-Rede-Planejamento, Desenvolvimento Político e Sustentabilidade. Publicado em O Município no século XXI: cenários e perspectativas, pela FPFL-CEPAM, São Paulo 1999.

Escola Politécnica Engenharia de Construção Civil: www.pcc.usp.br/pesquisas/areas/materiais-componentes-construcao-civil Acesso em 11/08/2013. 


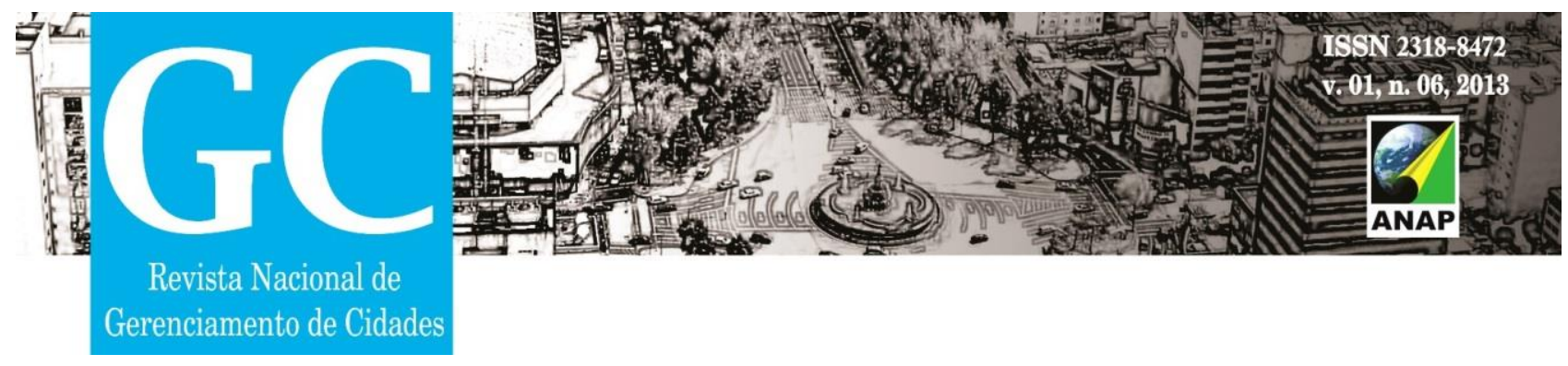

SOUZA, U. E. L. Como Medir a Produtividade da Mão-de-Obra na Construção Civil. Departamento de Engenharia de Construção Civil da Escola Politécnica da Universidade de São Paulo, São Paulo, 2001.

SOUZA, U. E. L e DEANA, F. D. Levantamento do Estado da Arte: Consumo de Materiais. Tecnologias para construção habitacional mais sustentável, projeto Finep 2386/04, São Paulo, 2007.

SOUZA, U. E. L. Produtividade e Custos dos Sistemas de Vedação Vertical. Tecnologia e gestão na produção de edifícios: vedações. PCC-EPUSP, pp. 237-48 São Paulo, 2001.

SORIANO, A. J. S. e SILVA, L. F. Projetos de Desenvolvimento Sustentável: Projeto de Uso Racional dos Recursos Naturais ou apenas Desenvolvimento? Departamento de Agronomia UNESP/REGISTRO, 2000. 